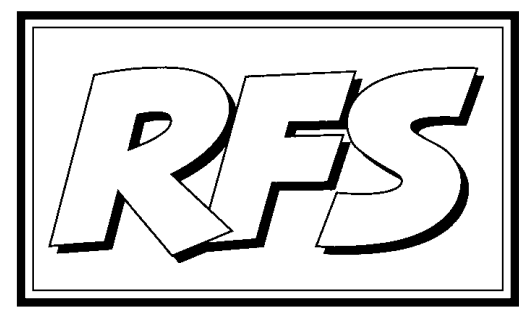

Revista de Fomento Social, 58 (2003), 181-186

\title{
La reconstrucción de Irak y el papel de Naciones Unidas
}

INTERMÓN OXFAM

La guerra en Irak continúa y, a pesar de que su desenlace es todavía incierto, ya se está debatiendo cómo debe llevarse a cabo la reconstrucción del país. Este documento propone principios sobre la forma en que la comunidad internacional debería asistir al pueblo de Irak para que establezca su propia administración después de la guerra. No intenta definir un modelo preciso, sino que las propuestas están basadas en nuestra experiencia y en las lecciones aprendidas en Kosovo, Bosnia, Timor Oriental y Afganistán, así como en la experiencia de Oxfam Internacional en la reconstrucción inmediata y a medio plazo de Irak después de la primera guerra del Golfo.

La reconstrucción de Irak será una tarea difícil. No sólo será necesario hacer frente a los daños causados por la guerra, sino que también habrá que superar un legado de 25 años de gobierno de Sadam Hussein, 12 años de sanciones de Naciones Unidas, la falta de un movimiento político iraquí unido que pueda asumir el gobierno y las profundas divisiones que esta guerra ha provocado en el seno de Naciones Unidas y de la comunidad internacional en 
general. Así mismo, si no se intenta solucionar la inestabilidad regional y en particular el conflicto entre Israel y Palestina, el desarrollo a largo plazo en Irak y en la región se verá frustrado.

Una reconstrucción exitosa dependerá de dos factores:

- El liderazgo de Naciones Unidas. Naciones Unidas debe disponer de un mandato claro durante el periodo inmediatamente posterior a la guerra, con el fin de establecer pronto una autoridad de transición. Naciones Unidas debería desempeñar un papel crucial en el apoyo a la reconciliación nacional, el restablecimiento de una nueva administración civil y la protección de la población.

- La reconstrucción. La responsabilidad de los costes directos de la guerra debe ser asumida por EEUU, Reino Unido, Australia y sus aliados. Sin embargo, el éxito de la reconstrucción dependerá del protagonismo y liderazgo de los propios iraquíes en el proceso, y del apoyo continuado de la comunidad internacional. Este apoyo debe estar coordinado por Naciones Unidas e incluir, entre otras medidas, ayuda para el desarrollo a largo plazo y condonación de la deuda, para hacer posible la reconstrucción económica y social, garantizar la protección de la población civil y promover la igualdad de género y el refuerzo de la sociedad civil.

\section{La necesidad del liderazgo de Naciones Unidas}

Liderazgo político. Intermón Oxfam cree que Naciones Unidas debe desempeñar un papel de liderazgo en el periodo inmediatamente posterior a la guerra, ya que tiene la experiencia y la legitimidad para ayudar a establecer rápidamente una administración iraquí representativa y responsable. Mientras que los Estados Unidos, el Reino Unido y sus aliados carecen de ellas.

Intermón Oxfam considera que en el corto periodo que medie entre el final del conflicto y el establecimiento de una autoridad de transición iraquí, Naciones Unidas debería tener plena autoridad sobre los asuntos civiles, legales, políticos, económicos y humanitarios dentro de Irak. Es crucial que Naciones Unidas reciba un mandato claro, creíble y realizable. Para ello, será necesaria una resolución del Consejo de Seguridad y, por lo tanto, el liderazgo de los miembros no permanentes dentro del Consejo que han 
mantenido buenas relaciones con todas las partes. La resolución no se aprobará si algún país intenta utilizarla como justificación post-hoc de la guerra.

Para que el mandato de Naciones Unidas sea realizable, también será necesario que el Gobierno de Estados Unidos respalde por completo, tanto política como financieramente, a Naciones Unidas y a las autoridades iraquíes que se establezcan. Si no es así o si se tiene la percepción de que Naciones Unidas actúa bajo la autoridad de Estados Unidos, Naciones Unidas se verá abocada al fracaso.

Recomendamos que se establezca una autoridad de transición iraquí a través de un diálogo nacional que incluya a los dirigentes políticos y de la sociedad civil de todos los sectores de la sociedad iraquí. Esta autoridad debe estar comprometida a formar un gobierno transparente y responsable a través de unas elecciones, y ser capaz de reactivar la economía, de proteger a todos los civiles y de proporcionar servicios básicos adecuados a mujeres y a hombres, incluyendo asistencia humanitaria cuando sea necesario. Naciones Unidas será de gran ayuda a una autoridad iraquí, especialmente en las áreas de construcción de consenso, de reconciliación nacional y de promoción de la participación activa de las mujeres en el gobierno desde el principio.

Debería recordarse que, hasta que se establezca una autoridad de Naciones Unidas o iraquí, los poderes ocupantes tendrán plena responsabilidad sobre todos los aspectos relacionados con el bienestar de la población civil, tal como establece el Derecho Internacional Humanitario en las Convenciones de Ginebra ${ }^{1}$.

Protección. Después de la guerra seguirán produciéndose graves amenazas para la seguridad de las personas en todo el país. Como en conflictos anteriores, podría producirse una escalada de tensiones étnicas, represalias políticas y violencia sexual. Es vital evitar que se produzca un vacío en la protección de los civiles durante el periodo de transición.

Podría ocurrir que Naciones Unidas no tuviera la capacidad de establecer y mantener la seguridad y la protección de la población civil. En tal caso, deberían hacerse cargo de ello Estados Unidos o las fuerzas aliadas, en

1 Documento de InTERmón OXfam $\mathrm{n}$ - 41, Irak: relaciones entre ayuda humanitaria y fuerzas militares, marzo de 2003. 
primera instancia. No obstante, como en Kosovo, es importante que estas fuerzas militares actúen bajo la autoridad de Naciones Unidas o coordinadas con Naciones Unidas. Ello evitaría el conflicto entre la divergencia de objetivos y prioridades de las autoridades civiles y militares.

Naciones Unidas debería establecer un marco legal y jurídico provisional para la defensa de los derechos humanos. En el desarrollo de dicho marco deberían participar dirigentes iraquíes, hombres y mujeres, para garantizar que refleje todas las aspiraciones y sensibilidades culturales y religiosas.

Administración civil. Tan pronto como sea posible, la autoridad de transición iraquí debería establecer una administración civil. En la medida de lo posible, esta administración debería basarse en estructuras administrativas y sociales existentes. Si la autoridad iraquí de transición no se forma rápidamente, Naciones Unidas deberá encargarse del establecimiento de una administración civil.

Tanto en Kosovo como en Afganistán, Naciones Unidas ha sido criticada por enviar a trabajadores internacionales inexpertos y con poca conciencia cultural, para dirigir las administraciones civiles desplazando a trabajadores nacionales competentes y expertos. No hay motivo para repetir los mismos errores en Irak: los trabajadores de la administración pública iraquí parecen cualificados y competentes, reflejando los niveles relativamente altos de educación en la sociedad iraquí.

No obstante, a la autoridad de transición o a Naciones Unidas les espera un papel incómodo: el establecimiento y la aplicación de los criterios por los que los funcionarios podrán volver a trabajar -excluyendo a aquellos que estén implicados en violaciones de los derechos humanos o en casos flagrantes de corrupción.

\section{Criterios para el éxito de los esfuerzos de reconstrucción}

Apropiación por parte de los iraquíes. La cuestión fundamental para el éxito de la reconstrucción es la apropiación y liderazgo del proceso por parte de los propios iraquíes, junto con el apoyo a largo plazo de la comunidad internacional. Este principio afecta a todas las fases de reconstrucción y a todos los actores, incluyendo a los donantes internacionales, el Banco Mundial y el Fondo Monetario Internacional. Existe el riesgo de que se repitan los errores cometidos en Timor Oriental, donde los actores nacionales fueron dejados de lado. 
Reconstrucción económica y social. Habrá una necesidad urgente de reactivar la economía nacional y local, de hacer frente a la creciente deuda externa iraquí ${ }^{2}$, de reparar las infraestructuras dañadas y de hacer que los servicios sociales básicos funcionen. La ayuda internacional es esencial para llevar a cabo esta tarea. Sin embargo, la ayuda tendrá un mayor impacto si se canaliza, al principio, a través de Naciones Unidas, y si se utiliza para emplear a trabajadores locales y para adquirir productos locales siempre que sea posible. Sólo debería recurrirse a trabajadores internacionales cuando no puedan encontrarse profesionales iraquíes con las competencias técnicas necesarias.

Estos mismos criterios afectan a la siguiente etapa de reconstrucción a mayor escala. Irak necesitará asistencia internacional de los donantes e inversiones privadas para volver a poner en marcha el sector petrolero y reactivar la agricultura y la industria. Las inversiones privadas sólo se producirán si los países ricos dan garantías en un contexto tan inseguro e incierto. Los ingresos por el petróleo iraquí deberían invertirse en la reconstrucción y el desarrollo del país a largo plazo, y no en la reparación de daños directos provocados por la guerra, que debería ser financiada por Estados Unidos, Reino Unido, Australia y sus aliados.

La necesidad de liderazgo y apropiación iraquí contrasta fuertemente con los planes del Gobierno estadounidense de controlar la primera fase de reconstrucción económica y asegurarse de que sean empresas de Estados Unidos y de sus aliados las que recojan los dividendos de la reconstrucción.

Logro de seguridad y protección. Las estrategias de reconstrucción deben prestar especial atención a la seguridad de la población iraquí. Es imprescindible que los fondos para la reforma del sector de la seguridad, así como para la reforma judicial y legal, estén disponibles con celeridad. Por otra parte, dicha reforma debe incluir la investigación y reciclaje de militares, policías y jueces.

A poyo a la igualdad de género. Las mujeres deben desempeñar un papel esencial en la reconstrucción de Irak. Intermón Oxfam cree que su participación será crucial en la formación de un gobierno responsable y orientado a cubrir las necesidades básicas de la población. No obstante, la plena participación de las mujeres en el gobierno y en la reconstrucción social requiere

2 Se calcula que la deuda externa de Irak se sitúa entre 100.000 y 200.000 millones de dólares, lo que la convierte en una de las mayores del mundo. 
un fuerte estímulo y sensibilidad cultural. Naciones Unidas debe garantizar los recursos y la formación adecuados para el cumplimiento de sus compromisos sobre la igualdad de género.

En concreto, el Departamento de Justicia y la policía necesitarán formación y recursos para tratar asuntos relativos a violaciones sexuales y a violencia doméstica. El Ministerio de Educación debería destinar los recursos adecuados para la educación de las niñas, una de las inversiones más eficaces para conseguir el desarrollo. Este aspecto es especialmente aplicable a un país como Irak, que contaba con logros importantes en el campo de la educación y de la participación de las mujeres, pero donde en los últimos años el analfabetismo ha aumentado hasta un $50 \%$.

Financiación. Para el éxito de la reconstrucción y para la eficacia de los futuros gobiernos iraquíes y del papel de Naciones Unidas, es fundamental tanto la provisión de ayuda adecuada como la condonación de la deuda por parte de la comunidad internacional, especialmente antes de que los ingresos provenientes del petróleo crezcan sustancialmente. Los principales partidarios de esta guerra en Irak tienen la responsabilidad desuministrar los fondos necesarios para la reconstrucción a corto y largo plazo. Sin embargo, los otros países ricos que se han opuesto a la guerra harían a ellos mismos y al pueblo iraquí un flaco favor si rechazan participar en la ayuda liderada por Naciones Unidas en Irak. 